\title{
Investigation of the earthquake sequence off Miyagi prefecture with historical seismograms
}

\author{
Hiroo Kanamori ${ }^{1}$, Masatoshi Miyazawa ${ }^{2}$, and Jim Mori ${ }^{2}$ \\ ${ }^{1}$ Seismological Laboratory, California Institute of Technology, Pasadena, California, USA \\ ${ }^{2}$ Disaster Prevention Research Institute, Kyoto University, Kyoto, Japan
}

(Received January 6, 2006; Revised March 30, 2006; Accepted April 23, 2006; Online published February 2, 2007)

\begin{abstract}
We investigated the old seismograms of several earthquakes which occurred offshore of Miyagi prefecture in 1933 (June 18, 21:37 UT), 1936 (Nov. 2, 20:45 UT), 1937 (July 26, $19: 56$ UT), 1978 (June 12, 08:14 UT), and 2005 (Aug. 16, 02:46 UT). A characteristic earthquake model for the sequence of the 1936, 1978, and several other earlier events is the basis of the recent forecast by the Earthquake Research Committee (2003) that "The probability of the occurrence of another similar earthquake in the next 30 years is $99 \%$ ". To assess the validity of the characteristic earthquake model, we compared the waveforms, size and other characteristics of these earthquakes recorded at Pasadena, DeBilt, Abuyama, Aso, Weston, Strasbourg, and Christchurch. We conclude that (1) The 1978 event is 3 to 4.5 times larger (in seismic moment) than the 2005 event; (2) The 1936 and the 2005 events are about the same size and are fairly close in location; (3) The 1937 event is smaller than the 1936 event, and is significantly deeper, possibly as deep as $90 \mathrm{~km}$. In contrast, the 1933 event is significantly shallower than the 1936 event. The differences between these events are too large to justify the use of a simple characteristic earthquake model for the probabilistic forecast. The seismic slip rate in this area and along the adjacent subduction zone to the south is about $1 / 4$ of the plate convergence rate, which has an important implication for the long-term seismic hazard in this area.
\end{abstract}

Key words: Miyagi-Oki earthquakes, characteristic earthquake, probabilistic forecast, asperity.

\section{Introduction}

A remarkable earthquake sequence with $M=7+$ events offshore of Miyagi prefecture, Japan, was recognized by the Earthquake Research Committee of the Headquarters for Earthquake Promotion (hereafter, referred to as Earthquake Research Committee (ERC)) in 2000. Figure 1 shows the general area and the location of the 1978 event, one of the events in the sequence. Through the investigations of the extent of tsunamis, intensity distributions, and instrumental data (for recent events), the following sequence of earthquakes has been documented: $1793(8.2,7.6), 1835$ (7.3), 1861 (7.4), 1897 (7.4, 7.8), 1936 (7.4, 7.0), 1978 (7.4, 7.4), 2005 (7.2, 7.0). The first number in the parenthesis is the magnitude $\mathrm{M}$ assigned by ERC, and the second number is the tsunami magnitude given by Abe (1988, 1999, personal communication, 2005). These earthquakes are generally called the Miyagi-ken-Oki earthquakes (Offshore Miyagi Prefecture earthquakes), but hereafter we call them just the Miyagi-Oki earthquakes. Note that the average recurrence interval before the year 2000 is $37 \pm 7$ years. On the basis of this approximate regularity, ERC made a tentative calculation with the result that the probability of having the next Miyagi-Oki earthquake before the end of 2030 is larger than $90 \%$ (report dated Nov. 27, 2000, http://www.jishin.go.jp/main/index.html). Then, in the

Copyright (c) The Society of Geomagnetism and Earth, Planetary and Space Sciences (SGEPSS); The Seismological Society of Japan; The Volcanological Society of Japan; The Geodetic Society of Japan; The Japanese Society for Planetary Sciences; TERRAPUB report of June 11, 2003, ERC updated the calculation and reported that the probability of having another Miyagi-Oki earthquake during the 30 year period after June 1, 2003 is $99 \%$. (see also Table 2.2.2-1 on page 54 of the report http://www.jishin.go.jp/main/chousa/05mar_yosokuchizu/ bunsatsu1-1.pdf.) This situation is similar to that of the Parkfield sequence in the U.S (e.g., Bakun et al., 2005). On August 16, 2005, 27 years after the 1978 event, a $M_{w}=7.2$ earthquake occurred in the same area, and it appeared that the forecast was fulfilled. However, the 2005 event was about 3 to 4.5 times smaller in seismic moment than the 1978 event, and ERC decided that the 2005 event was not the expected event, and the forecast remains in effect.

Implicit in this forecast is that these earthquakes are "characteristic" earthquakes, which means that they occurred at the same location with a similar size and mechanism. Thus, if the size of the 2005 event is very different from the 1978 event, it is not the expected characteristic event. This is probably the logic behind the recent decision of ERC. Then, an obvious question is how "characteristic" are these events, especially how the 1936 event compares with the 1978 and 2005 events. Now, several lines of evidence suggest that the 1936 event is considerably smaller than the 1978 event. In relation to this, two other events, one in 1937 and the other in 1933 both with $M=7+$ which occurred in approximately the same area, were brought to the attention of seismologists (Umino et al., 2006). One argument is that the characteristic event which was supposed to occur in the 1930's was split into 3 events $(1933,1936$, 


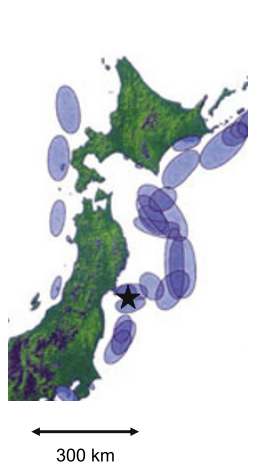

1978 vs. 2005 (PAS Press-Ewing 30-90)
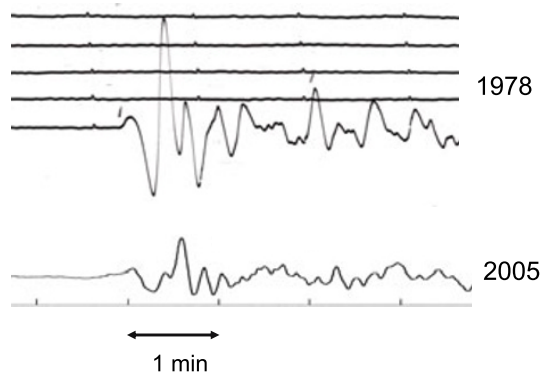

Fig. 1. Location of the 1978 earthquake (star) and comparison of the vertical component Press-Ewing (30-90) seismograms for the 1978 and 2005 events. Elliptic symbols indicate the source areas of damaging earthquakes. All the events in the Miyagi-Oki sequence (1933, 1936, $1937,2005)$ are located within about $50 \mathrm{~km}$ of the 1978 event.

1933

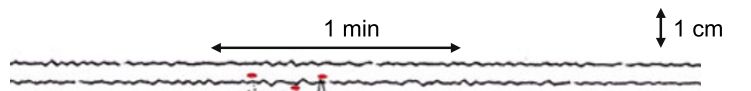

1936

1937
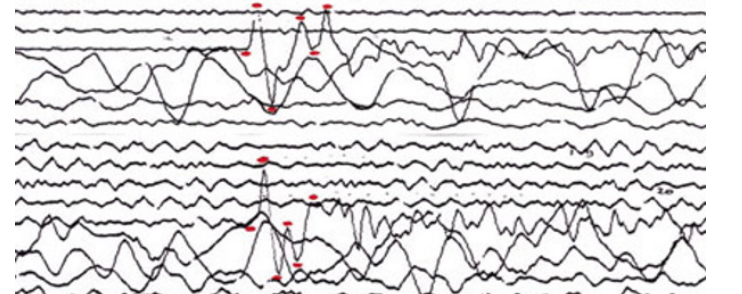$$
\text { (n) }
$$

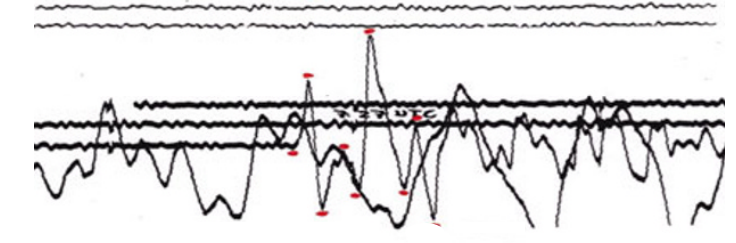

2005

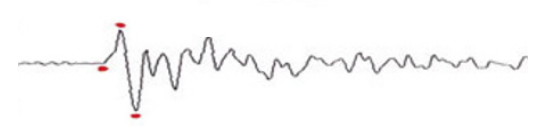

Fig. 2. Comparison of $P$ waves of the Miyagi-Oki earthquakes recorded on the vertical component Galizin seismograms at DeBilt.

and 1937). If this was the case, the 2005 event could be one of the split "characteristic" events, and more events like the 2005 event are expected in the near future.

Once the original definition of "characteristic" events is relaxed, we may end up with all kinds of possibilities. A critical information for resolving this problem can be obtained from careful inspection of the seismograms of the 1933, 1936, 1937, 1978, and 2005 earthquakes. In this paper we investigate the seismograms recorded at several distant stations, Pasadena, DeBilt, Weston, Strasbourg, and Christchurch and two Japanese stations, Abuyama and Aso.

\section{Mechanism and Size of the 1978 and 2005 Earthquakes}

For the two most recent earthquakes, the 1978 and the 2005 events, the mechanism and seismic moment have been determined well using the modern digital records. The Harvard CMT catalog (http://www.seismology.harvard.edu)

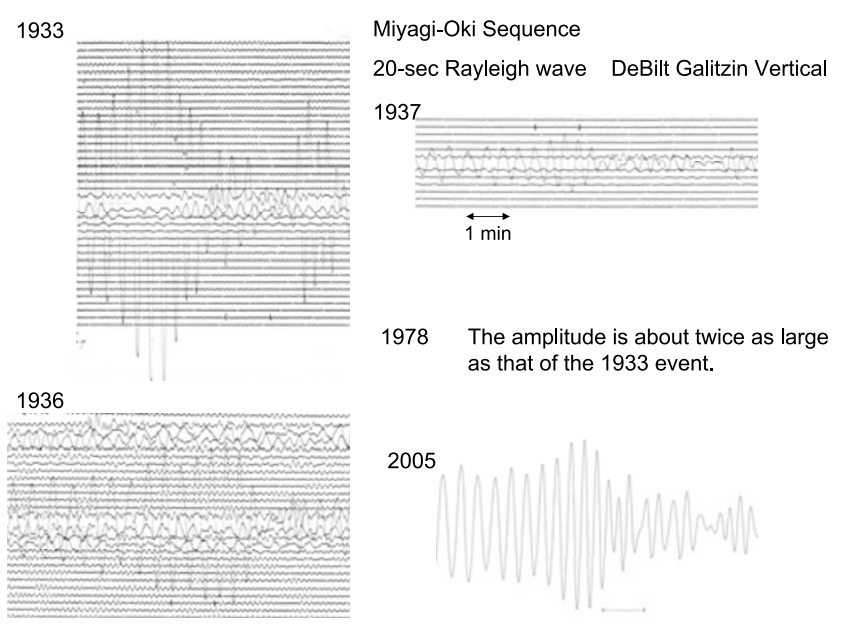

Fig. 3. Comparison of Rayleigh waves of the Miyagi-Oki earthquakes recorded on the vertical component Galizin seismograms at DeBilt. The amplitude of the Rayleigh waves of the 1978 event (not shown) is about twice as large as that of the 1933 event.

Table 1. Amplitude data determined from DeBilt records. The numbers in the parentheses are the amplitudes relative to the 1936 event. The ratio of Rayleigh to $P$ wave amplitudes is listed as $A_{s} / A_{b}$.

\begin{tabular}{cccc}
\hline Event & $\begin{array}{c}P \text { wave } \\
(\text { Vertical }, \mathrm{cm})\end{array}$ & $\begin{array}{c}\text { Rayleigh wave } \\
(\text { Vertical }, \mathrm{cm})\end{array}$ & $\begin{array}{c}\text { Ratio } \\
\left(A_{s} / A_{b}\right)\end{array}$ \\
\hline 1933 & $1.1(0.92)$ & $24(2.2)$ & 22 \\
1936 & $1.2(1.0)$ & $11(1.0)$ & 9.2 \\
1937 & $0.67(0.56)$ & $3.9(0.4)$ & 5.8 \\
1978 & $2.1(1.8)$ & $48(4.4)$ & 23 \\
2005 & $0.98(0.82)$ & $11(1.0)$ & 11 \\
\hline
\end{tabular}

shows that the mechanisms are similar, and seismic moments $M_{0}$ are $3.37 \times 10^{20} \mathrm{Nm}$ and $7.43 \times 10^{19} \mathrm{Nm}$, for the 1978 and 2005 events, respectively. The seismic moment of the 1978 event has been estimated also by Seno et al. (1980) $\left(M_{0}=3.1 \times 10^{20} \mathrm{Nm}\right)$, Kanamori and Given (1981) $\left(2.16 \times 10^{20} \mathrm{Nm}\right)$, and Yamanaka and Kikuchi (2004) $\left(2.3 \times 10^{20} \mathrm{Nm}\right)$. Thus, the 1978 event is 3 to 4.5 times larger than the 2005 event in $M_{0}$. The mechanisms suggest that these events represent a rupture on the subduction boundary between the Pacific and the Eurasia (or the North American) plate near the bottom of the inter-plate seismogenic zone. The difference is also clearly displayed by comparison of the Press-Ewing (30-90) seismogram for the 1978 event and the simulated Press-Ewing seismogram for the 2005 event at Pasadena as shown in Fig. 1. (The Press-Ewing seismograph having a pendulum with a period of $T_{p}=30 \mathrm{sec}$ and a galvanometer with a period of $T_{g}=90$ sec is called the 30-90 system.) The direct comparison of seismograms, as shown in Fig. 1, is the basis of inter-event comparisons at different stations for older events.

\section{Inter-event Comparisons}

\subsection{DeBilt}

The seismological observatory at DeBilt, Holland, had been operating a Galitzin seismograph since the early 1920's until 1994. Since 1994, a broad-band seismograph replaced the Galitzin seismograph from which the Galizin seismograph can be simulated (Dost and Haak, 2006). 
1936 vs. 2005 (PAS Benioff LP 1.2-22 EW x3000)

$\mathrm{L}$

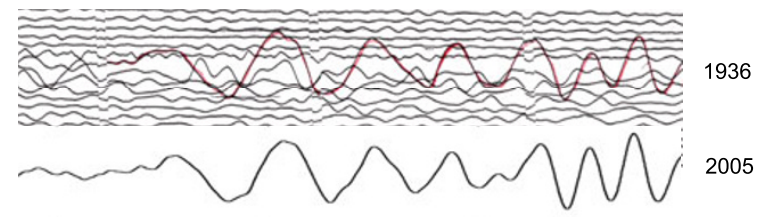

$\mathrm{R}$

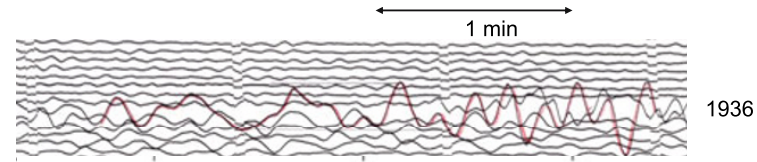

Comparison of 6-sec Wood-Anderson (EW) at PAS

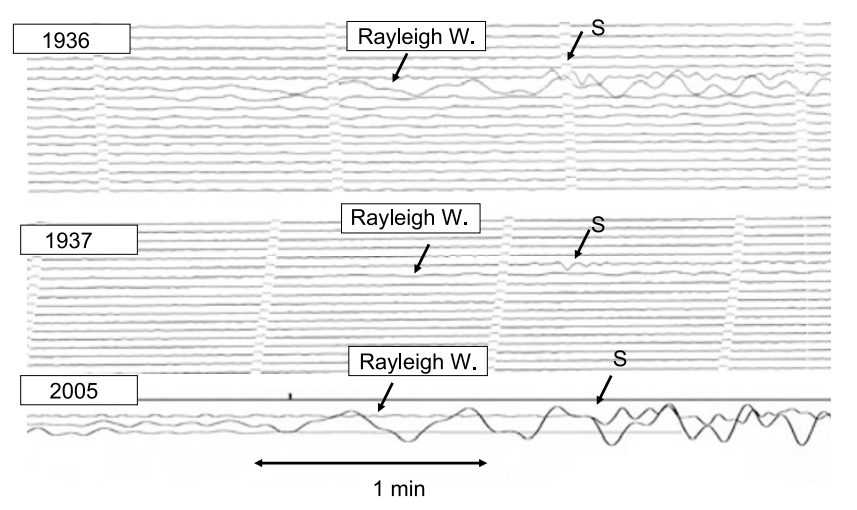

Fig. 5. Comparison of the EW component of 6-sec Wood-Anderson seismograms recorded at Pasadena for the 1936, 1937 and 2005 events. The seismogram for the 2005 is simulated from the broad-band seismogram.

on the EW component of the Benioff long-period (1.2-22) seismograms (The Benioff seismograph having a pendulum with a period of $T_{p}=1.2 \mathrm{sec}$ and a galvanometer with a period of $T_{g}=22 \mathrm{sec}$ is called the 1.2-22 system.). Unfortunately, this seismograph is not one of the standard instruments of the Caltech network, and the peak magnification is not documented. This seismograph is a predecessor to the standard Benioff long-period (1-90) system which has a peak magnification of 3000 . We assumed the same gain factor for this seismograph. Since the gain factor of this type of instrument was in general chosen to be as high as possible to the extent that microseismic noise does not dominate the record, the use of the same maximum gain for the 1.2-22 and 1-90 systems is reasonable. The waveforms of both Love and Rayleigh waves are very similar between the 1936 and the 2005 events, suggesting that these two events are fairly similar. Since the wavelength of the surface waves is about $60 \mathrm{~km}$, the spatial resolution is probably of the order of about $10 \mathrm{~km}$. Both events have approximately the same amplitude, but the 2005 event has a slightly larger amplitude at short period than long period, suggesting that the 2005 event is slightly shallower.

Figure 5 shows the comparison of the 1936, 1937 and 2005 events recorded on the EW component of the 6-sec Wood-Anderson seismograph. According to the station information the instrument constants are $\left(T_{0}=6 \mathrm{sec}, h=\right.$ 0.8 , and $V=800$ ) where $T_{0}$ is the natural period, $h$ is the damping constant and $V$ is the static magnification. The amplitude of the Rayleigh wave of the 2005 event is about twice as large as that of the 1936 event. The Rayleigh wave of the 1937 event is very small suggesting that this event is much deeper than the 1936 and the 2005 events.

The amplitude ratio of the 1936 to 2005 events is different between Figs. 4 and 5. This difference must be due to incorrect instrument constants used for the simulation. McComb and West (1931) lists the gain factor of 400 for the Pasadena $6 \mathrm{sec}$ Wood-Anderson instrument. If this is the correct value, the results from the Benioff seismogram and the Wood-Anderson seismogram are compatible.

Figure 6 compares the $P$ waveforms on short-period Benioff seismograms where the dominant period is about 1

Figure 4 compares Love and Rayleigh waves recorded 
Table 2. The amplitudes determined from Pasadena seismograms. The numbers in the parentheses are the amplitudes relative to the 1936 event.

\begin{tabular}{|c|c|c|c|c|c|c|}
\hline \multirow[t]{2}{*}{ Event } & \multirow{2}{*}{$\begin{array}{c}\text { Press-Ewing } \\
\text { (Vertical, cm) } \\
P \text { wave }\end{array}$} & \multicolumn{2}{|c|}{$\begin{array}{c}\text { Benioff LP } \\
(\mathrm{EW}, \mathrm{cm})\end{array}$} & \multirow{2}{*}{$\begin{array}{c}6 \mathrm{sec} \text { WA } \\
(\mathrm{EW}, \mathrm{cm}) \\
\text { Rayleigh W }\end{array}$} & \multicolumn{2}{|c|}{$\begin{array}{c}\text { Benioff SP } \\
\text { (Vertical, cm) }\end{array}$} \\
\hline & & Love W. & Rayleigh W. & & $P$ wave & Rayleigh W. \\
\hline 1936 & & $2.0(1.0)$ & $1.3(1.0)$ & $0.53(1.0)$ & $1.2(1.0)$ & 0.18 \\
\hline 1937 & & & & small & $0.62(0.52)$ & $\leq 0.02$ \\
\hline 1978 & 5.0 & & & & $2.1(1.8)$ & 0.5 \\
\hline 2005 & 1.6 & $1.8(0.9)$ & $1.3(1.0)$ & 0.5 to 1.0 & $1.4(1.2)$ & 0.25 (1.0 to 1.9$)$ \\
\hline
\end{tabular}

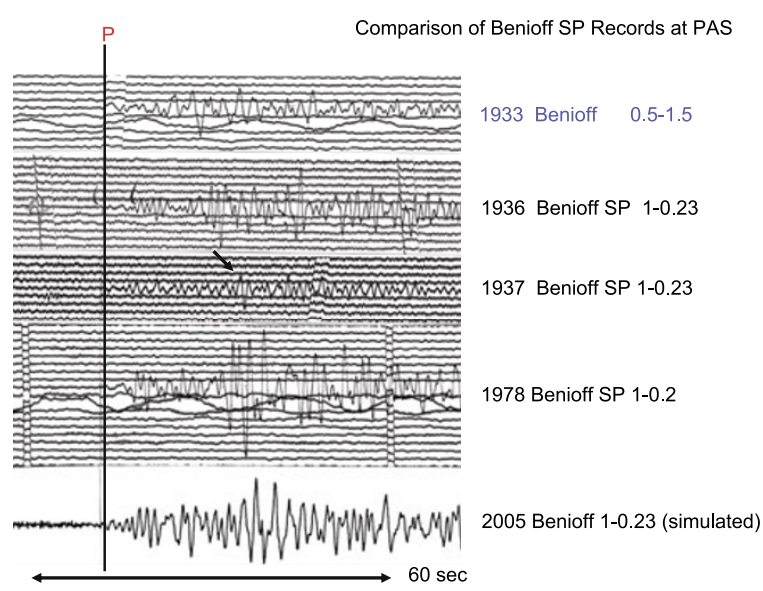

Fig. 6. Comparison of $P$ waves recorded on the vertical component short-period Benioff seismograms at Pasadena. Note that the response of the seismogram for the 1933 event is slightly different. The arrow indicates the $p P$ phase.

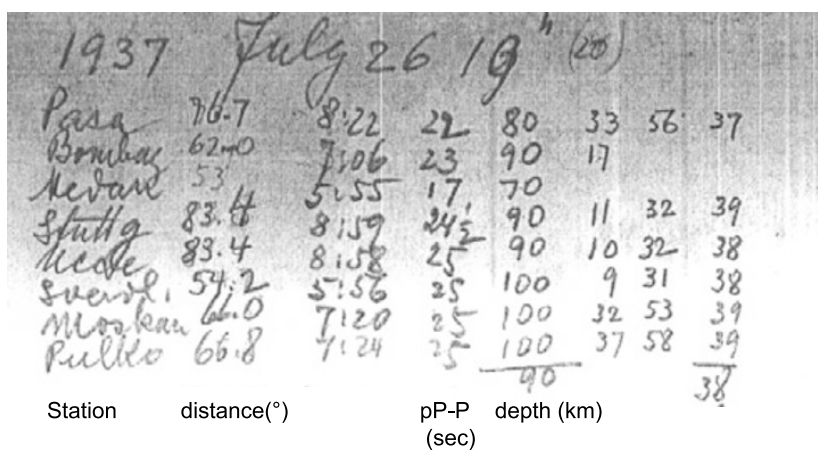

Fig. 7. The depth phase, $p P$, listed on the Gutenberg's note pad (Note Pad \# 44, page 29). Station name, distance (in deg.), $p P-P$ time (in sec), and the estimated depth (in $\mathrm{km}$ ) are listed on the 1st, 2nd, 4th, and 5th columns respectively (courtesy of Caltech Archive).

to 2 sec. Except for the 1933 event, all the events were recorded with essentially the same seismograph, and the waveforms can be compared directly. In this period range, the similarity of the waveforms breaks down, indicating that these events are dissimilar on space and time scales corresponding to this period. Rayleigh waves can be seen on the records of the 1936, 1978, and 2005 events, but cannot be seen on the 1937 record; it is below the noise level, about $0.02 \mathrm{~cm}$.

We now investigate the depth phase. The depth phases such as $p P$ and $s P$ are often useful for estimation of the depth. A distinct phase at about $22 \mathrm{sec}$ after the $P$ onset (marked by an arrow) is seen on the 1937 seismogram. If
Table 3. Amplitude data from the Weston seismograms. The numbers in the parentheses are the amplitudes relative to the 2005 event.

\begin{tabular}{ccc}
\hline Event & $\begin{array}{c}\text { Benioff LP } \\
\text { Rayleigh W. } \\
\text { (vertical, cm) }\end{array}$ & $\begin{array}{c}\text { Benioff SP } \\
P \text {-wave } \\
\text { (vertical, cm) }\end{array}$ \\
\hline 1936 & $0.4 \mathrm{~cm}(0.11) ?$ & $0.5(0.77)$ \\
1937 & $1.0 \mathrm{~cm}(0.27)$ & too noisy \\
2005 & $3.65 \mathrm{~cm}(1.0)$ & $0.65(1.0)$ \\
\hline
\end{tabular}

this is the $p P$ phase, it would put the depth of this event at about $80 \mathrm{~km}$. Beno Gutenberg listed a $p P$ phase at 8 teleseismic stations including Pasadena on his notepad used for Gutenberg and Richter's (1954) book "Seismicity of the Earth and Associated Phenomena", and they assigned a depth of $90 \pm 30 \mathrm{~km}$ to this event. Figure 7 shows the relevant part of the Gutenberg's notepad. These observations, together with the small surface wave amplitude, suggest that the 1937 event is significantly deeper than the 1936 and 2005 events. Table 2 summarizes the amplitude data from Pasadena.

\subsection{Weston Observatory, Boston College}

The Weston Observatory of Boston College recorded the 1936 and 1937 events with the Benioff short-period (10.25 ) and the Benioff long-period (1-60) seismographs. For the 2005 event, records from a broad-band instrument (CMG 40T) are available from which we can simulate the Benioff seismograms. The amplitudes of 20-sec Rayleigh waves on the long-period seismograms and $P$ waves on the short-period seismograms are listed in Table 3.

The amplitude of the Rayleigh wave of the 1936 event is very small. The station operation began in late 1936, and the records for the 1936 event are not clearly labeled as the vertical component of the Benioff long-period instrument. It is possible that the recording was just experimental at the time.

Except for this, the amplitude ratios are consistent with those from Pasadena and DeBilt.

\subsection{Strasbourg}

The station at Strasbourg operated Wiechert threecomponent seismographs, and the seismograms for the 1933, 1936 and 1937 events are available. Table 4 lists the amplitudes of $P$ and Rayleigh waves recorded on the vertical component.

The ratios are consistent with those estimated from the seismograms at Pasadena and DeBilt.

\subsection{Christchurch}

The vertical component Galitzin seismograms show that the peak-to-trough amplitude of the Rayleigh wave is $8 \mathrm{~cm}$ 

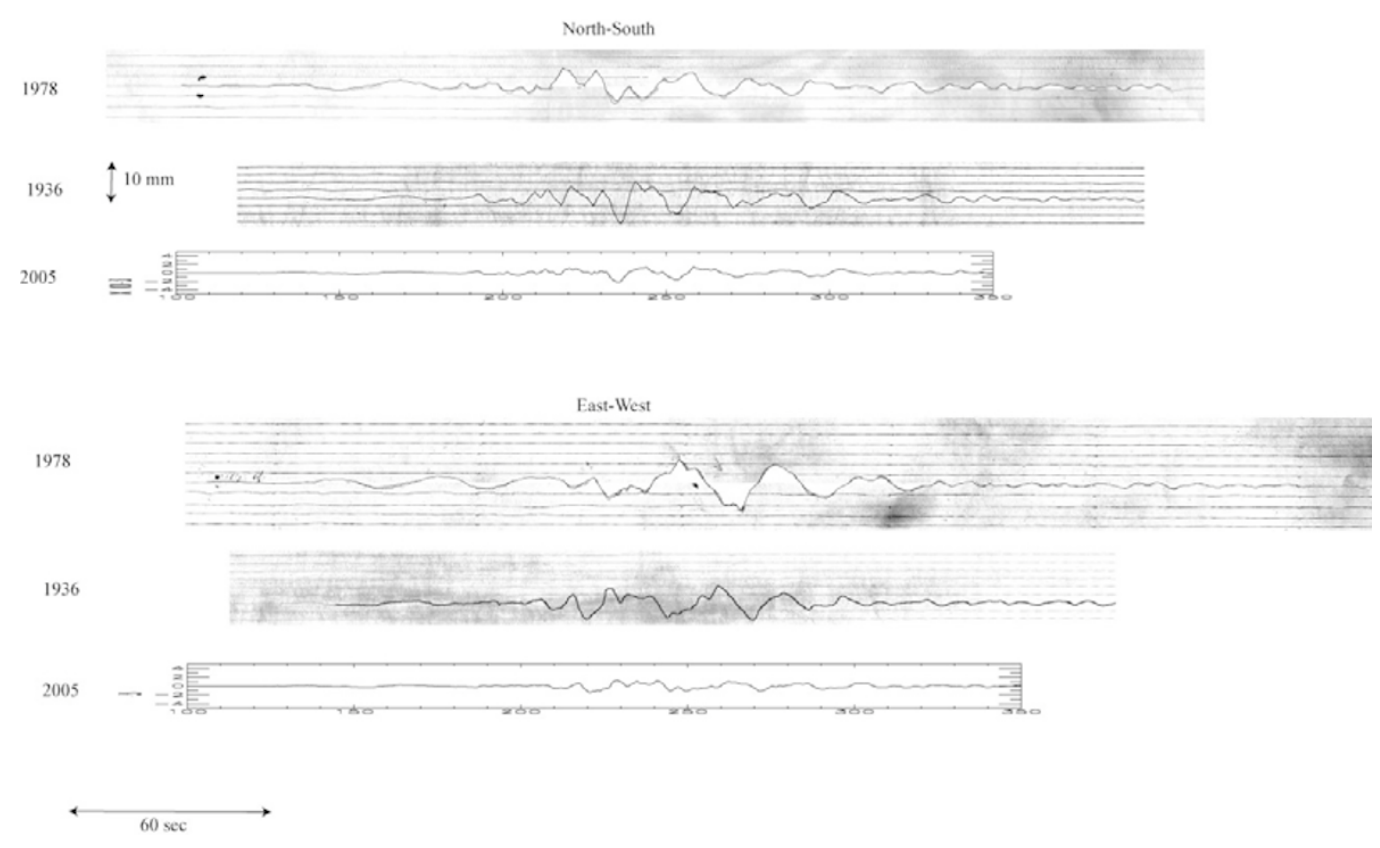

Fig. 8. Comparison of the Abuyama Sassa seismograms for the 1936, 1978, and 2005 events. The seismograms for the 2005 event are simulated from the STS-1 seismogram.

for the 1936 event and $7 \mathrm{~mm}$ for the 1937 event. The $P$ wave amplitude (peak-to-trough) is $11 \mathrm{~mm}$ for the 1936 event. For the 1937 event, the $P$-wave is buried in the microseismic noise, which is about $4 \mathrm{~mm}$ in peak-to-trough amplitude. The ratio of the Rayleigh wave of the 1937 event to the 1936 event is about 0.1 which is comparable to that observed at Pasadena.

\subsection{Abuyama}

The Abuyama observatory of Kyoto University operated two seismographs, a low-gain long-period Sassa seismograph, and a Wiechert seismograph. Both of these seismographs recorded the 1936 and 1978 events. The 2005 event was recorded with a STS-1 broad-band seismograph of the Japanese F-net. We simulated the Sassa and Wiechert seismograms from the broad-band records. Figures 8 and 9 compare these records. The main phase on the Sassa seismograms is the surface wave with a period of about 26 sec, and that on the Wiechert seismograms is the PL wave. First, we compare the 1978 and 2005 events for calibration purposes because the size and the mechanism of these two events are determined well with modern seismograms. We measure the combined amplitude of the two horizontal components by $\sqrt{A_{N}^{2}+A_{E}^{2}}$ where $A_{E}$ and $A_{N}$ are the amplitudes of E-W and N-S components, respectively. The ratio is 3.1 for both Sassa and Wiechert records. The ratio for the $P L$ wave is determined by smoothing the waveform. The period of the smoothed waveform is about 30 to $35 \mathrm{sec}$. This ratio is consistent with the ratio of $M_{0}$ for these events.

Next, we determine the amplitude ratio of the 2005 to 1936 events. The ratio is 0.38 from the Sassa seismograms and 0.63 from the Wiechert seismograms. These ratios are considerably smaller than the ratios estimated from teleseis-
Table 4. Amplitudes of $P$ and Rayleigh waves recorded at Strasbourg on the vertical component Wiechert seismograms.

\begin{tabular}{ccc}
\hline Event & $\begin{array}{c}P \text { wave } \\
\text { (vertical }, \mathrm{cm})\end{array}$ & $\begin{array}{c}\text { Rayleigh Wave } \\
\text { (vertical, cm) }\end{array}$ \\
\hline 1933 & $0.44(0.75)$ & $0.31(1.94)$ \\
1936 & $0.59(1.0)$ & $0.16(1.0)$ \\
1937 & $0.28(0.47)$ & $0.06(0.38)$ \\
\hline
\end{tabular}

mic records. We will discuss this difference later together with the ratio from the Aso seismograms.

3.7 Aso

A Wiechert seismograph $\left(T_{0}=4.6 \mathrm{sec}\right)$ recorded the 1936 and 1978 events. For the 2005 event, we simulated the Wiechert seismogram from a CMG-40T seismogram recorded essentially at the same site. Figure 10 compares these records. The amplitude ratio of 20 -sec surface waves of the 1978 to the 2005 events is 1.91 which is considerably smaller than what is expected from the moment ratio of these two events. The Wiechert seismograph was not calibrated frequently in the 1970 's, so that it is possible that the pendulum period was shorter than $4.6 \mathrm{sec}$ leading to a smaller magnification at long period. The ratio of the 20 -sec surface wave of the 2005 to the 1936 event is 0.74 which is comparable to that of the ratio estimated from the PL wave at Abuyama, but is larger than that estimated from the surface waves at Abuyama. In general, the 2005/1936 ratio from the regional stations, Abuyama and Aso, is considerably smaller than that from teleseismic stations. This difference could be due to the errors in the calibration or due to the difference in the excitation of teleseismic and regional surface waves. Because of the complex 3-D structure in the 
Abuyama Wiechert
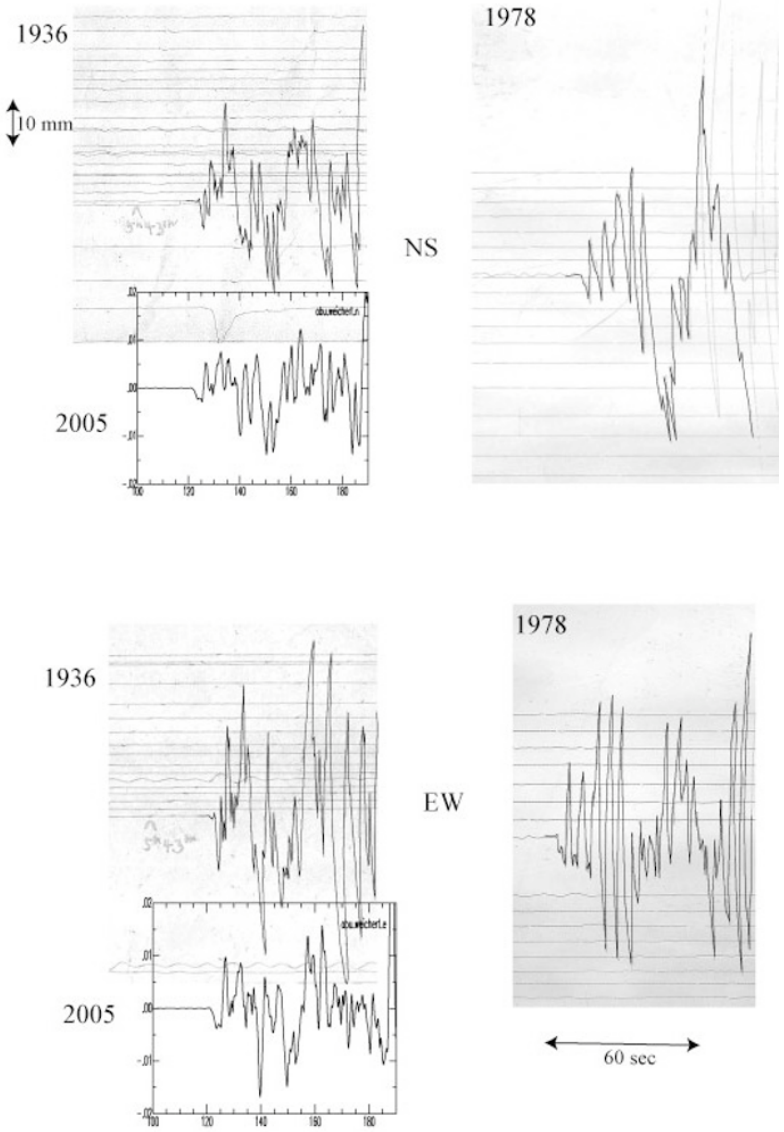

Fig. 9. Comparison of the Abuyama Wiechert seismograms for the 1936, 1978, and 2005 events. The seismograms for the 2005 event are simulated from the STS-1 seismogram. The long period wave is the $P_{L}$ wave, and the amplitude ratio is determined from the smoothed trace.

Table 5. Surface-wave amplitude data for the 1936 event documented by Gutenberg.

\begin{tabular}{ccc}
\hline Station & Distance $\left(^{\circ}\right)$ & Amplitude $(\mu \mathrm{m})$ \\
\hline Moscow & 68 & 150 \\
Pulkovo & 68 & 200 \\
La Paz & 146 & 140 \\
Helwan & 81 & 80 \\
Kew & 81 & 200 \\
Stuttgart & 82 & 130 \\
Hamburg & 80 & 200 \\
Uccle & 82 & 200 \\
DeBilt & 82 & 280 \\
Göttingen & 81 & 110 \\
\hline
\end{tabular}

source region, a slight difference in the location, especially in the depth, of the event may cause a significant difference in the excitation of surface waves at regional distances.

\section{Amplitude data}

The difference in size between the 1978 and the 2005 is well established. Then the size comparison between the 1936 and 2005 events is the key issue for testing the "characteristic" earthquake model. To further compare the 1936

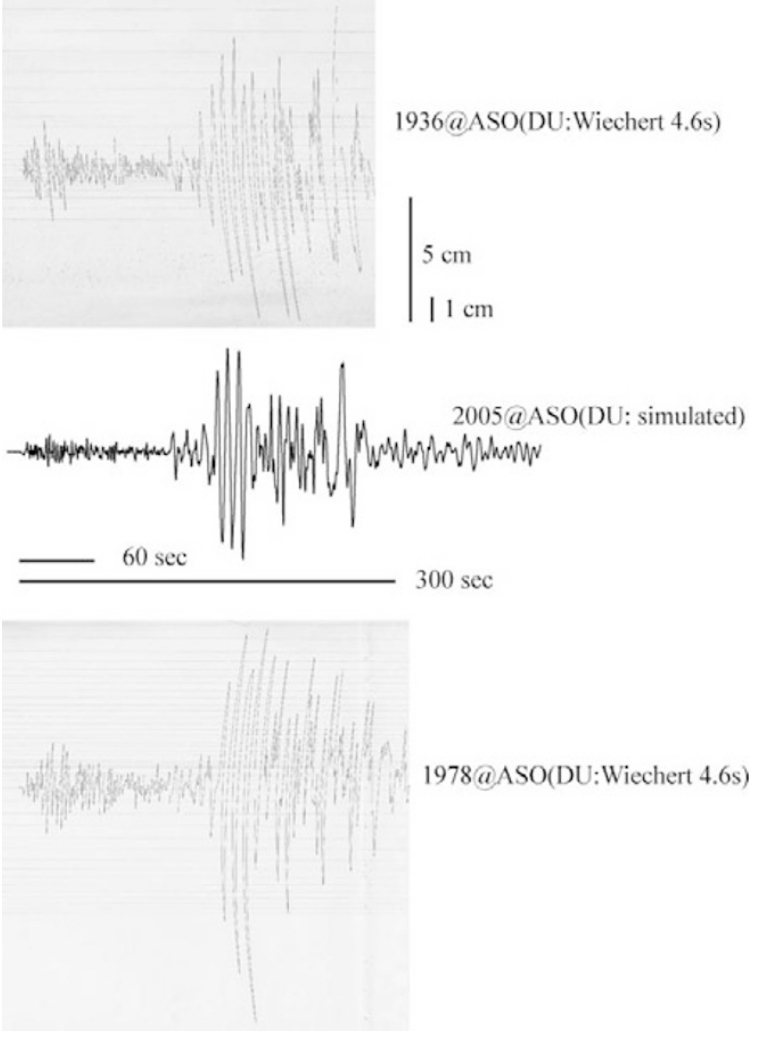

Fig. 10. Comparison of the Aso Wiechert seismograms for the 1936, 1978, and 2005 events. The seismogram for the 2005 event is simulated from the CMG-40T seismogram.

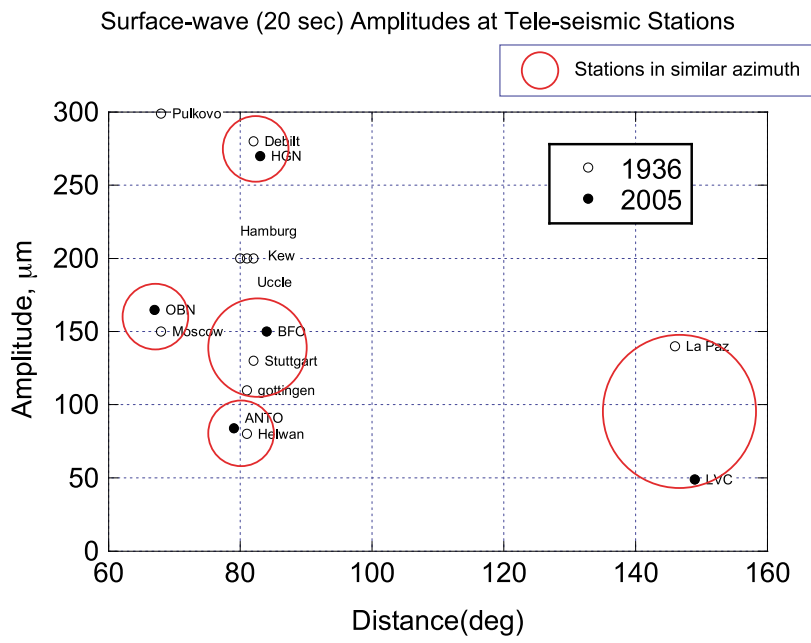

Fig. 11. Comparison of the surface-wave amplitudes of the 1936 and the 2005 events. The amplitudes are about the same between the two events at nearby stations. The reason for the discrepancy at La Paz is unknown.

and the 2005 events, we examined the amplitude data documented by Gutenberg in his notepad (Table 5).

To compare the 1936 event with the 2005 event, we chose several IRIS GSN stations which recorded the 2005 event and are close to the stations which recorded the 1936 event, and simulated the horizontal components of the Galitzin seismograms from the broad-band seismograms. Then we measured the surface-wave amplitudes in the way described by Gutenberg (1945). Figure 11 shows the comparison. 
Comparison of Simulated Galitzin Seismograms between 2005 (top) and 2003 (bottom) Events

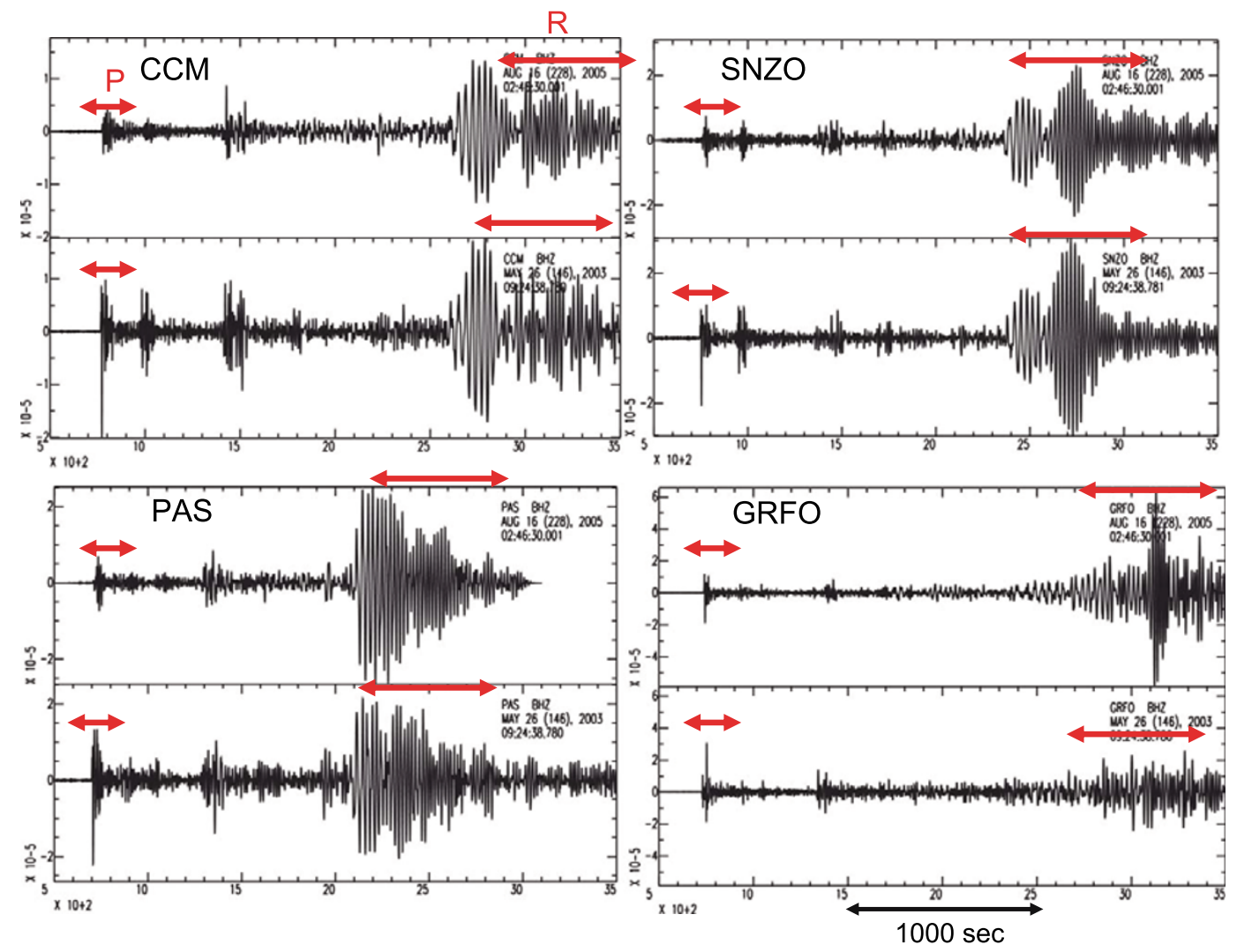

Fig. 12. Comparison of the waveforms of the 2005 inter-plate event (top) and the 2003 intra-plate event (bottom) at four stations distributed over a wide azimuthal range. The records are simulated Galitzin vertical component records. The windows from which the amplitude ratio, $\left(A_{s} / A_{b}\right)$, is measured are indicated. The vertical scale gives the amplitude in meters on a vertical component of the Galitzin seismograph $\left(T_{p}=T_{g}=12\right.$ sec $)$ with a peak gain of 1 .

Except La Paz, the amplitudes of the 1936 and the 2005 events agree within $10 \mu \mathrm{m}$. The reason for a factor of 3 difference in the amplitude at La Paz is unknown.

\section{The 1937 Event, Intra-plate Event?}

As we mentioned earlier, the small surface waves and Gutenberg's report of $p P$ phase suggest that the 1937 event is probably deep. If it is indeed deep, it is probably not a thrust event on the subduction boundary, and could be an intra-plate event which occurred within the subducting plate. We tested this hypothesis by comparing the amplitude ratio of surface waves (Rayleigh wave) to body waves between the 2005 event (inter-plate event) and a known intra-plate event which occurred on May 26, 2003, off Miyagi prefecture $\left(M_{w}=7.0,38.821 \mathrm{~N}, 141.651 \mathrm{E}\right.$, Depth, $72.0 \mathrm{~km})$. This event is located about $60 \mathrm{~km}$ north of the 2005 earthquake. We simulated Galitzin vertical component records using the data from the GSN stations, and measured the amplitude ratio, $\left(A_{s} / A_{b}\right)$, of surface waves to $P$ waves. Figure 12 compares the waveforms at four stations distributed over a wide azimuthal range. The ratios are smaller for the 2003 intra-plate event than the 2005 interplate event. This trend is the same as that seen for the 1937 event and the 1936 event, and suggests that the 1937 event is a deep intra-plate event like the 2003 event. To quantify this statement, we take the ratios $\left(A_{s} / A_{b}\right)$ for 7 stations which are distributed over a wide azimuthal range, and take the av- erage of them. The ratio of the average ratio of $\left(A_{s} / A_{b}\right)$ for the 2003 event to the 2005 event, $\left(A_{s} / A_{b}\right)_{2003} /\left(A_{s} / A_{b}\right)_{2005}$ is 0.41 . If the 2003 and 2005 are at the same depth, this ratio should be 1 . This ratio can be compared with the ratio, $\left(A_{s} / A_{b}\right)_{1937} /\left(A_{s} / A_{b}\right)_{1936}$, for the 1937 and 1936 events, which is 0.63 from DeBilt (from Table 1) and $\leq 0.2$ from Pasadena (from Table 2). From this comparison, we can conclude that the depth relation between the 2003 and 2005 events is similar to that between the 1937 and 1936 events. The almost complete absence of surface waves at Pasadena suggests that the 1937 event can be even deeper.

\section{Discussion and Conclusion}

Although the amplitude and waveform data obtained from several stations are not completely consistent, the results from different stations are generally consistent, considering the difficulties in recovering the instrument characteristics of old seismograms. The results from teleseismic records show:

1) The 1978 event is 3 to 4.5 times larger (in $M_{0}$ ) than the 2005 event.

2) The 1936 and the 2005 events are about the same size and, judging from the waveforms, they are fairly close in location and with a similar mechanism, but not identical.

3) The 1933 and the 1937 events are significantly different in character from the 1936 event. The 1937 event is smaller than the 1936 event, and is significantly deeper, pos- 
Table 6. Comparison of the events in the Miyagi-Oki sequence

\begin{tabular}{ccc}
\hline Event & Relative size & Depth \\
\hline 1933 & 1 & shallower \\
1936 & 1 & $\sim 40 \mathrm{~km}$ \\
1937 & 0.3 to 0.5 & deeper $(70$ to $90 \mathrm{~km})$ \\
1978 & 3 to 4.5 & $\sim 40 \mathrm{~km}$ \\
2005 & 1 & $\sim 40 \mathrm{~km}$
\end{tabular}

sibly as deep as $90 \mathrm{~km}$. It is most likely an intra-plate event within the subducting plate. In contrast, the 1933 event is significantly shallower than the 1936 event. Table 6 summarizes the overall results.

The regional records from Abuyama and Aso indicate that the surface-wave amplitude of the 2005 event is 0.38 to 0.74 times that of the 1936 event. The difference in the amplitude ratio obtained from regional and teleseismic data could be due to inaccurate calibration. However, if the calibration of the instrument is correct, then the smaller ratio from regional data than from teleseismic records indicates that the location and the mechanism must be different to cause different excitation for teleseismic and regional distances.

Out of the 5 events of the sequence $(1933,1936,1937$, 1978, 2005), only the 1936 and 2005 events look similar. Thus, by a common sense definition, this sequence is not a characteristic sequence. In the "characteristic earthquake" model used for long-term probabilistic forecasts, some variations are implicitly allowed, but the variations suggested by our analysis are too large to justify a simple characteristic earthquake model for the Miyagi-Oki sequence.

Umino et al. (2006) relocated the main shocks and the aftershocks of the 1933, 1936, 1937, and 1978 earthquakes using the $S$ - $P$ times reported by the Japan Meteorological Agency and those read from the records at two nearby stations. They found that the aftershock areas of the 1933, 1936, and 1937 events partly overlap with that of the 1978 event. Their conclusions on the 1933 and the 1936 events are qualitatively consistent with our results. Regarding the 1937 event, Umino et al. (2006) argue on the basis of the depth of some of the aftershocks (figures 4 and 5 of Umino et al.) and the main shock mechanism (figure 6 of Umino et al.) that the 1937 event occurred on the plate boundary, like the 1936 and the 1978 events. This conclusion is different from our conclusion. Since the interpretations of the old seismic data are inevitably subject to large uncertainties because of the limited quality and the uncertain timing and instrument characteristics, whether the 1937 event is an inter-plate or intra-plate event is ultimately a matter of judgment. Our conclusion is based on the $p P$ phase and the amplitude ratio of the surface to body waves.

Takemura and Kanda (2006) investigated the intensity distribution of the events of the Miyagi-Oki sequence including the 1936, 1937, and 1978 events. Their conclusion is qualitatively compatible with that of Umino et al. (2006) and ours. Regarding the 1937 event, Takemura and Kanda (2006) found that the area of intensity 5 (JMA scale) of the 1937 event is smaller than that of the 1936 event (figure 2 of Takemura and Kanda), and its source area is shifted to the west with respect to the 1936 event (figure 4 of Takemura and Kanda). This result is consistent with our finding that the 1937 event is smaller and probably deeper than the 1936 event.

Despite some differences in detail between the three studies, the overall conclusion that the 1933, 1936, 1937, and 1978 are different enough not to be treated as simple characteristic earthquakes is supported by all of these studies.

This sequence probably has a more significant implication for the long-term seismic hazard in northeastern Japan. Even if the earthquakes are not characteristic, these events determine the seismic slip rate in this area for the past 70 years. The question is how this seismic slip rate compares with the plate motion rate in this area. A simple calculation as is done by Kanamori (1977) indicates that it is only about $1 / 4$ of the plate convergence rate. A similar ratio applies to the $200 \mathrm{~km}$ segment of the subduction zone south of off Miyagi prefecture. Very few large damaging earthquakes seem to have occurred for the past 1400 years along this segment. In contrast, recent analyses of GPS data suggest (Mazzotti, 2000; Nishimura et al., 2004) that plate coupling in northeastern Japan is almost $100 \%$ (i.e., no aseismic slip) to a depth of about $50 \mathrm{~km}$. These observations suggest: (1) Three quarters of the plate motion is taken up by aseismic slip which was not resolved by the GPS analysis, or (2) The plate boundary is coupled $100 \%$, and the accumulated strain will be eventually released by either large megathrust events, large tsunami earthquakes, or large silent earthquakes.

Acknowledgments. We thank Katsuyuki Abe for providing us with key information on the old Japanese events. We thank Bernard Dost (DeBilt), Luis Rivera (Strasbourg), Brian Ferris (Christchurch), and John Ebel and Dina Smith (Weston) for locating and sending us the copies of the seismograms used in this study. Anthony Guarino helped us find old seismograms from the Caltech seismogram archive. The copies of the pages of the Gutenberg notepad used in this study were provided by the Archives of the California Institute of Technology. For the study of the 2003 and 2005 events, we used the Japanese F-Net seismograms, and the Global Seismic Network seismograms of the Incorporated Research Institutions for Seismology. We thank Luis Rivera, Toru Matsuzawa, and Keiko Kuge for careful and thoughtful reviews. Hiroo Kanamori acknowledges the support of the Japan Society of Promotion of Science under its Eminent Scientists Award program, which allowed his visit to the Disaster Prevention Research Institute, Kyoto University.

\section{References}

Abe, K., Tsunami magnitudes and the quantification of earthquake tsunamis around Japan, Bull. Earthquake Res. Inst. Tokyo Univ., 63, 289-303, 1988.

Abe, K., Quantification of historical tsunamis by the Mt scale, Zisin, 52, 369-377, 1999.

Bakun, W. H., B. Aagaard, B. Dost, W. L. Ellsworth, J. L. Hardebeck, R. A. Harris, C. Ji, M. J. S. Johnston, J. Langbein, J. J. Lienkaemper, A. J. Michael, J. R. Murray, R. M. Nadeau, P. A. Reasenberg, M. S. Reichle, E. A. Roeloffs, A. Shakal, R. W. Simpson, and F. Waldhauser, Implications for prediction and hazard assessment from the 2004 Parkfield earthquake, Nature, 437, 969-974, 2005.

Dost, B. and H. W. Haak, Comparing waveforms by digitisation and simulation of waveforms for four Parkfield earthquakes observed in station DBN, the Netherlands, Bull. Seismol. Soc. Am., 96, S50-S55, 2006.

Gutenberg, B., Amplitudes of surface waves and magnitude of shallow earthquakes, Bull. Seismol. Soc. Am., 35, 3-12, 1945. 
Gutenberg, B. and C. F. Richter, Seismicity of the Earth and Associated Phenomena, 2 ed., 310 pp., Princeton University Press, Princeton 1954.

Kanamori, H., Seismic and Aseismic Slip along Subduction Zones and their Tectonic Implications, 163-174 pp., AGU Geophys. Mono. 1977.

Kanamori, H. and J. W. Given, Use of long-period surface waves for rapid determination of earthquake source parameters, Phys. Earth Planet. Int., 27, 8-31, 1981.

Mazzotti, S., X. Le Pichon, P. Henry, and S. Miyazaki, Full interseismic locking of the Nankai and Japan-west Kurile subduction zones: An analysis of uniform elastic strain accumulation in Japan constrained by permanent GPS, Journal of Geophysical Research-Solid Earth, 105, 13159-13177, 2000.

McComb, H. E. and C. J. West, List of seismological stations of the world, Bulletin of the National Research Council, 1-119, 1931.

Nishimura, T., T. Hirasawa, S. Miyazaki, T. Sagiya, T. Tada, S. Miura, and K. Tanaka, Temporal change of interplate coupling in northeastern Japan during 1995-2002 estimated from continuous GPS observations, Geophysical Journal International, 157, 901-916, 2004.

Seno, T., K. Shimazaki, P. Somerville, K. Sudo, and T. Eguchi, Rupture process of the Miyagi-oki, Japan, earthquake of June 12, 1978, Phys. Earth Planet. Int., 23, 39-61, 1980.

Takemura, M. and K. Kanda, Characteristics of seismic intensity distribution from the earthquake ( $M=7.2)$ off Miyagi Prefecture, Japan, on August 16th, 2005, and its short-period seismic wave radiation zone, Zisin, 2006 (submitted) (in Japanese).

Umino, N., T. Kono, T. Okada, J. Nakajima, T. Matsuzawa, N. Uchida, A. Hasegawa, Y. Tamura, and G. Aoki, Revisiting the three M 7 Miyagioki earthquakes in the 1930s: Possible seismogenic slip on asperities that were re-ruptured during the $1978 \mathrm{M}=7.4$ Miyagi-oki earthquake, Earth Planets Space, 58, this issue, 1587-1592, 2006.

Yamanaka, Y. and M. Kikuchi, Asperity map along the subduction zone in northeastern Japan inferred from regional seismic data, J. Geophys. Res., 109, B07307, doi:07310.01029/02003JB002683, 2004.

H. Kanamori (e-mail: hiroo@gps.caltech.edu), M. Miyazawa, and J. Mori 